\title{
Effect of Spirulina platensis Supplementation on Nutritional and Biochemical Parameters of Under Five Years Malnourished Children from an Orphanage in Douala, Cameroon
}

\author{
Kana Sop Marie Modestine ${ }^{1,{ }^{*}}$, Namadi Muhamadu ${ }^{1}$, Tetanye Ekoe $^{2}$ and Gouado Inocent ${ }^{1,{ }^{*}}$ \\ ${ }^{1}$ University of Douala, Faculty of Science Laboratory of Biochemistry; ${ }^{2}$ University of Yaoundé, Faculty of \\ Medecine and Biomedical Science, Cameroon
}

\begin{abstract}
Malnutrition is the underlying cause of $50 \%$ of morbidity and mortality in the under-five age group. Its frequencies have been increasing in young Cameroon children during the past three decades (stunting $\geq 38 \%$; anemia $\geq$ $58 \%$; Zinc $\geq 69 \%$ and vitamin $A \geq 38 \%$ )

We carried out a prospective study to assess the supplementation effect of Spirulina platensis on moderate and mild malnutrition on children under five years old. Seven children (4-5 years) were enrolled in this study. Children were enrolled in nutritional rehabilitation for 25 days. Each child received $8 \mathrm{~g}$ of supplement daily, $4 \mathrm{~g}$ in the morning and $4 \mathrm{~g}$ in the evening. Anthropometric and haematologic parameters were measured before and after rehabilitation.

Mild and moderate malnutrition, wasting and underweight was seen in 4 children anthropometrically (no child was stunted) and haematologically in all 7 children before rehabilitation started. The children were weighted four times (First week at enrollment (W1), week 2 (W2), Week 3 (W3), Week 4 (W4)). After 25 days, a significant gain in weight was observed and varying from $17.21 \pm 2.00 \mathrm{Kg}\left(\mathrm{W}_{1}\right)$ to $18.45 \pm 2.07 \mathrm{Kg}\left(\mathrm{W}_{2}\right)$ and from $18.143 \pm 1.77 \mathrm{Kg}\left(\mathrm{W}_{3}\right)$ to $18.67 \pm$ $1.93 \mathrm{Kg}\left(\mathrm{W}_{4}\right)$ with their respective $\mathrm{P}$ - values at $0.02\left(\mathrm{~W}_{2}\right), 0.02\left(\mathrm{~W}_{3}\right)$ and $0.04\left(\mathrm{~W}_{4}\right)$ after rehabilitation. The following biomarkers and their constants also showed a significant variation: calcium $(73.91 \pm 16.89 \mathrm{mg} / \mathrm{L}$ vs $88.41 \pm 14.83 \mathrm{mg} / \mathrm{L}(\mathrm{p}$ $=0.03)$, mean cell volume $(86.14 \pm 4.38 \mathrm{fl}$ vs $83.86 \pm 4.83 \mathrm{fl}(\mathrm{p}=0.04)$ and mean cell haemoglobin concentration $(32.10$ $\pm 0.38 \mathrm{~g} / \mathrm{dL}$ vs $34.27 \pm 3.35 \mathrm{~g} / \mathrm{dL}(\mathrm{p}=0.03)$ respectively before and after rehabilitation. Other biomarkers (proteins, haemoglobin, haematocrit, platelets, red blood cells, white blood cells, neutrophiles, eosinophiles, basophiles, monocytes, lymphocytes) had also increased in non a significant manner.
\end{abstract}

The study showed that spirulina platensis impact positively in the fight against malnutrition by improving weight and raising the blood content of biomarkers due to its high content of proteins (60-70\%) and pigments.

Keywords: Malnutrition, Spirulina platensis, Supplementation, Rehabilitation, Biomarkers, children.

\section{INTRODUCTION}

The world health organisation (WHO) defines malnutrition as the cellular imbalance between the supply of nutrients and energy and the body's demand to ensure growth, maintenance and specific function [1]. Malnutrition in children is the consequence of much food insecurity, which stems from poor quality, especially that which is poor in micronutrients [2] and quantity, severe and/or repeated infections or combinations of all three [3]. These conditions are linked to the standard of living and to insure maintenance of basic needs $[4,5]$.

According to UNICEF, $36 \%$ of children under the age of five were stunted in Cameroon, while $16 \%$ were underweight, and $7 \%$ were wasted [3].

However, in Cameroon, $12 \%$ of children in the richest quintile are stunted, highlighting that this is not an issue of food access, but caring practices and diseases control. In Cameroon under nutrition is the underlying cause for $50 \%$ of morbidity and mortality in

*Address correspondence to this author at the University of Douala, Faculty of Science Laboratory of Biochemistry, Cameroon; Tel: 237777428 73; Fax: (237)234 4075 69; E-mail: kanamod@yahoo.com, gouadoi@yahoo.fr

ISSN: 2223-3806 / E-ISSN: 1927-5951/15 the under - five age group [3]. The solution for this situation however, is nutritional intervention (supplementation, fortification and diversification of foodstuffs) which helps in rehabilitating the children. For supplementation intervention to reduce malnutrition, many dietary supplements have been proposed (including Spirulina sp., Moringa oleifera, Glycine max etc.). Among them, Spirulina platensis was found to be the best supplement, due to several advantages it possessed, notably high content of proteins, micronutrient (such as calcium, magnesium etc) pigments and so on [6]. There is today a strong need to expand the facilities available for improving the child feeding patterns especially in the developing countries through formal education on how to best harness the locally available foods to supply the much needed nutrients [3]. An adequate feeding (balanced diet) reinforce the immune system in the fight against infection [7].

In its latest guidelines regarding the choice of foods and ingredients for moderately malnourished children, the WHO concluded (for the first time) that Spirulina could play a role in treating children with moderate malnutrition and recommended further investigation of this subject [8]. The WHO projects that spirulina will (C) 2015 Lifescience Global 
become one of the most curative and prophylactic components of nutrition in the 21 st century $[9,10]$.

Therefore, this let us to propose Spirulina platensis as a food supplement for the fight against malnutrition under a prospective study in Douala. In Cameroon, only one study has been done as far as spirulina is concern in the rehabilitation of Insulin resistance HIVinfected patient [11].

\section{Type of Study}

It is a prospective study carried out from 16 February to 9 March 2013 where by only seven children was enrolled. The study protocol was validated by the National Ethic Committee at Yaoundé under the research project entitle "FOOD BASE APPROACHES TO REDUCE CHILDHOOD NUTRIENT ENERGY MALNUTRITION IN CAMEROON». The approval was on the agreement that patient anonymity must be maintained, best clinical practice be ensured.

\section{Study Area}

The study took place in an orphany "orphelinat de COMPASSION", Douala, situated at TEXACO aeroport Douala (Cameroon). It embodied (orphanage) 22 children of varied ages, which were then separated into two groups: those below 5 years and those above. Seventeen children below 5 years were selected out of 22 and the former were further separated into seven healthy and ten malnourished. Blood was collected from seven while the last three refused. Four children were anthropometrically malnourished and all seven haematologically. The purpose of choosing an orphanage is due to the fact that children are in a closed environment where they can easily be rehabilitated, control and follow-up while children in the quarter are dispersed and unstable therefore may render the study ambiguous.

\section{MATERIAL AND METHODS}

Seven children were enrolled in the study. Their anthropometric measurement (weight and height) using Salter-scale $(1-120 \mathrm{Kg}$ Cap, AMSUA at $0,01 \mathrm{Kg})$ and tape were taken, while nutritional indices were calculated using Waterlow and Gomez formula for determination of malnutrition level. Blood sample were collected in order to determine the red blood cells counts, white blood cells count, platelets; percentage of: haematocrit, neutrophils, eosinophils, basophiles, monocytes and lymphocytes; concentration of: calcium, total proteins, haemoglobin, mean cell haemoglobin concentration, mean cell volume using URIT 810 (biomérieux) and $\mathrm{ABX}$ Micros 60 . This was done with the aim to identify malnourished children after the first analysis. Then, those children were rehabilitated with Spirulina platensis in order to compensate their deficiencies.

\section{Clinical Assessment}

Anthropometric measurements included weight, height and body mass index (BMI). Body height and weight were measured without shoes and stockings using height gauge (toise) and portable Salter scale (1 - $120 \mathrm{Kg}$ Cap, AMSUA at 0, $01 \mathrm{Kg}$ ) measure.

The measurements of height were made using height gauge (toise). The children were made to stand on a flat surface with feet parallel and with heels, buttocks and shoulders and backs of head touching the right tape. Measurements were taken to the nearest $0.1 \mathrm{~cm}$ (see Table 1).

A portable Salter scale measure was used for weight measurement. The subjects were made to stand on the platform of the scale erect without shoes and with minimum clothing, when the pointer was at zero. Measurements were taken to the nearest $0.1 \mathrm{~kg}$. The

Table 1: Nutritional Indices of the 7 Children According to Waterlow's and Gomez Classification of Malnutrition before and after Rehabilitation

\begin{tabular}{|c|c|c|c|c|c|c|c|c|c|}
\hline \multirow[t]{2}{*}{ Children } & \multirow[t]{2}{*}{ Sex } & \multirow{2}{*}{$\begin{array}{c}\text { Age } \\
\text { (years) }\end{array}$} & \multicolumn{2}{|c|}{ Weight (Kg) } & \multirow{2}{*}{$\begin{array}{c}\text { Height } \\
\text { (cm) }\end{array}$} & \multicolumn{2}{|c|}{ Weight-for-height (\%) } & \multicolumn{2}{|c|}{ Weight-for-age (\%) } \\
\hline & & & BR & AR & & BR & AR & BR & AR \\
\hline 1 & $M$ & 5 & 15.5 & 16.5 & 106 & 78.61 & 83.67 & 83.33 & 88.70 \\
\hline 2 & $M$ & 4 & 17 & 17.5 & 102 & 97.92 & 100.79 & 106.25 & 109.37 \\
\hline 3 & $M$ & 5 & 16 & 16.5 & 109 & 78.92 & 81.38 & 86.02 & 88.70 \\
\hline 4 & $M$ & 4 & 15.5 & 16.5 & 108 & 77.16 & 100.12 & 83.33 & 103.13 \\
\hline 5 & $\mathrm{~F}$ & 5 & 20.5 & 21.5 & 114 & 100.45 & 105.35 & 114.52 & 120.11 \\
\hline 6 & $\mathrm{~F}$ & 5 & 19.5 & 20 & 122 & 89.29 & 91.58 & 108.93 & 111.73 \\
\hline 7 & $M$ & 4 & 16.5 & 18.5 & 107 & 90.60 & 101.57 & 103.13 & 115.62 \\
\hline
\end{tabular}

BR: Before Rehabilitation, M: Male, Weight-for-height: wasting, AR: After Rehabilitation, F: Female Weight-for-age: underweight. 
scale was standardized each time measurements were made (see Table 1). Anthropometric indices were calculated Gomez and Waterlow classifications of malnutrition were used. These include height-for-age, weight-for-age and weight-for-height. The measurements were made before and after rehabilitation (administration of spirulina).

\section{Biochemical Assays}

Four $\mathrm{mL}$ of venous blood were collected using sterile disposable $5 \mathrm{~mL}$ syringe under aseptic technique from peripheral vein of the subjects, and place in sterile plastic. The four $\mathrm{mL}$ blood was separated into two aliquots; $2 \mathrm{~mL}$ was poured into a test-tube containing anti-coagulant and the rest $2 \mathrm{~mL}$, into another not containing anti-coagulant for plasma and serum acquisition respectively. Collections were made before and after rehabilitation. The collected blood was taken to the nearest biochemical laboratory for treatment and conservation where it was centrifuged at the speed of $3600 \mathrm{rev} / \mathrm{min}$ at $4^{\circ} \mathrm{C}$ then stored at $-20^{\circ} \mathrm{C}$ until analysis. The concentration of the following blood parameters were measured: Calcium, total proteins, red blood cells count, white blood cells count, hemoglobin, haematocrit, and blood Constance (mean cell volume $(\mathrm{MCV})$, mean cell haemoglobin concentration (MCHC), mean cell content of haemoglobin $(\mathrm{MCCH})$.

Total Proteins were determined by Buiret Method that involves a Colorimetric quantitative determination of proteins giving an intensive violet-blue complex with copper salt in an alkaline medium while lodide was introduced as an antioxidant. The intensity of the color form was proportional to the proteins concentration in the sample measured at $540 \mathrm{~nm}$.

Concentration of calcium was determined by colorimetric quantitative analysis. Calcium gives intensive violet coloration in an alkaline medium by forming a complex with cresolphtalein whose intensity is proportional to calcium concentration. The measurement was made with spectrophotometer read at 570nm using URIT 810 spectrometer (Bioméreiux). Haemoglobin, haematocrit, Red Blood Cell (RBC), White Blood Cell (WBC), platelets, neutrophiles, eosinophiles, basophiles, monocytes, lymphocytes and blood constance were read directly from the instrument ABX Micros 60 used for this purpose.

All values obtained below the cut-off point indicated a deficiency consequently, malnutrition. The results of the two assays (before and after rehabilitation) are shown in Tables $\mathbf{1}$ and 2.

\section{Biological Material}

Spirulina was chosen in between others (Moringa oleifera and Glycin max) as material for this study and was supply by a care giver and trained mother for its production in Yaoundé. Among many food supplements proposed, notably, Moringa oleifera, Glycin max and Spirulina platensis, the latter was preferred due to its high content of proteins (55-70\%) and various micronutrients. Moringa and soy bean had low content of proteins (5.95 and 35\% respectively) compared to spirulina. Fifteen sachets of spirulina were bought for 75000CFA with each containing approximately $100 \mathrm{~g}$ of spirulina costing 5000CFA (equivalent of $10 \$ \mathrm{US}$ ). Before the rehabilitation started, three sachets were taken to Research Center of Food and Nutrition in Yaoundé, for the determination of protein contents. Result of the test showed that, the protein contents of the three sachets were respectively $52.66 \%, 53.05 \%$ and $55.84 \%$.

\section{Nutritional Rehabilitation with Spirulina $p$.}

\section{Preparation and Administration of Spirulina platensis}

Malnourished children from "Orphelinat la Compassion" were supplemented with spirulina. This monitoring was done to see the effect of nutritional supplementation on rehabilitation of children for a period of 25 days.

The mother responsible for the orphanage was given in weekly base, the sachets of weekly ration of $4 \mathrm{~g} \times 2(4 \mathrm{~g}$ in the morning and $4 \mathrm{~g}$ in the evening) $\times 25$ days of Spirulina platensis in powder form to be mixed in traditional food (vegetable, fruits etc) of the malnourished children. The dose given to one child was equivalent to 200 sachets of $4 \mathrm{~g}$ spirulina needed to appreciate absorption of nutrients while the dose for 7 children was 1400 sachets. Measurement of $4 \mathrm{~g}$ of spirulina was done using a balance for measuring foods. The content of proteins in $4 \mathrm{~g}$ of spirulina was $2.8 \mathrm{~g}$, while $8 \mathrm{~g}$ of spirulina contain $5.6 \mathrm{~g}$ of proteins. Eight grams $(4 \mathrm{~g} \times 2)$ was mixed in traditional meal or eaten solely daily, $4 \mathrm{~g}$ in the morning and $4 \mathrm{~g}$ in the evening to derive $5.6 \mathrm{~g}$ of proteins.

The methodology was described in the Figure 1 described.

\section{Duration of Administration}

The duration of administration lasted for 25 days. This allowed us to know whether the supply of different 


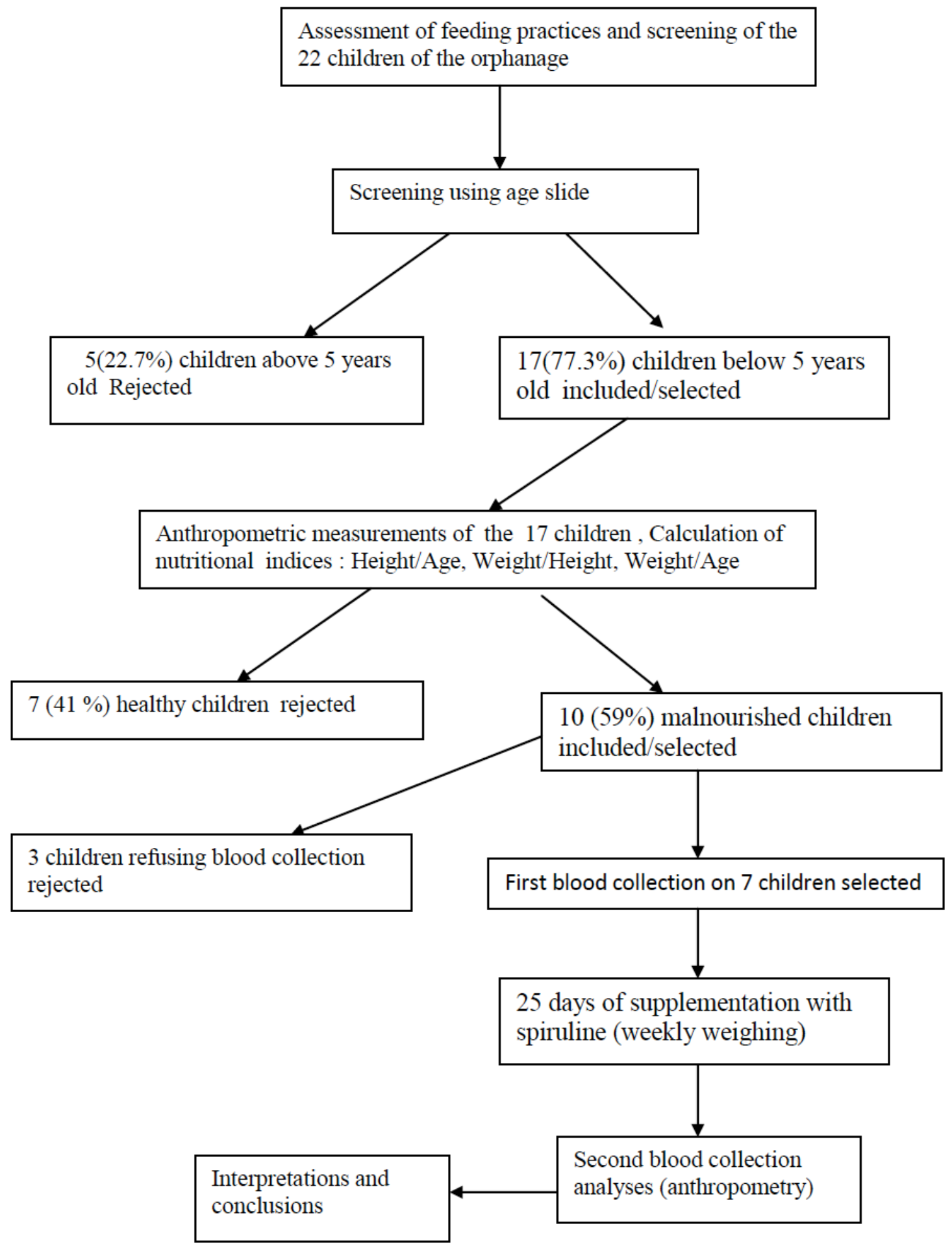

Figure 1: Schematic Protocol of Field Work.

type of nutrients has been filled despite the short duration of rehabilitation. The period taken for rehabilitation to be done was not sufficient to appreciate maximum gain in weight and absorption of deficient nutrient.

Four $\mathrm{mL}$ of blood were re-collected for the second time (after 25 days of rehabilitation) at the end of supplementation to test for the presence of micronutrients already mentioned above.

\section{Analysis and Interpretation of Data}

Statistical analyses of data were performed using Statview 5.0 (SAS Inc., USA). Spearman's correlation (IC95\%, p-value $\leq 0.05$ ), Row test of Wilcoxon (Non 
parametric test of appariated series) were used to analysed anthropometric and haematologic parameters. A p-value of $<0.05$ was interpreted as indicating statistically significant differences.

\section{RESULTS}

After we have gone through our study which was to assess the effect of spirulina platensis supplementation on nutritional and biochemical parameters of under five years malnourished children in Douala, Cameroon, two results, both anthropometrical and haematological before and after rehabilitation were obtained. The results of nutritional indices calculated from anthropometric data are summarized on the Table 1 below using to the classification of Waterlow and Gomez. The result showed the occurrence of malnutrition in 4 children (children 1, 3, 4 and 6) while the remaining three children $(2,5$ and 7$)$ were normal (See Table 1) as obtained from nutritional indices before rehabilitation and biochemical assay. Three children were moderately malnourished (Children 1, 3, and 4) and only one was mildly malnourished (child 6). A child was said to be moderately malnourished if his or her value of nutritional indices lied between $70-80 \%$ in the classification of waterlow (weight-for-height: wasting) and $60-74 \%$ in Gomez classification (weightfor-age: underweight) or mildly malnourished when it is between $80-90 \%$ in the classification of waterlow (weight-for-height: wasting) and $75-89 \%$ in Gomez classification (weight-for-age: underweight) respectively. The normal cut-off for the two respective classifications are $>90$ and $90-110 \%$. The results of anthropometry only give broad information of malnutrition while biochemical assay gives detail information. The latter showed the occurrence of malnutrition in all the children before the process of rehabilitation.
After administration of spirulina to the children, their nutritional indices (both weight-for-height and weightfor-age) were improved significantly and dependently with an increase in weight. From the table below Children 2, 4, 5, 6 and 7 had regained their normal weight-for-height (90\%), while children 1 and 3 continue to have mild malnutrition (80-90\%) despite the weight gain. The reason is that, the time taken for the process of rehabilitation was short if not all will have become normal. Children 2, 5, 6 and 7 had normal weight-for-age (90-110\%) while children 4,1 and 3 had mild malnutrition (75-89\%).

\section{Biochemical Assay after Rehabilitation}

After rehabilitation, a significant increase in calcium content, Mean Cell Volume (MCV) and Mean Cell Haemoglobin Concentration (MCHC) was observed (see Table 2 below). On the other hand non significant increased of proteins, haemoglobin, haematocrit, red blood cell, white blood cell, neutrophile, eosinophile, basophile, monocytes and lymphocytes was also observed as seen in Table 2 below.

\section{DISCUSSION}

After 25 days of rehabilitation with Spirulina platensis, an improvement in nutritional indices and an increase in immunological markers were observed in some of the children. Previous studies also reported increasement of anthropometric indices after supplementation with spirulina [11, 12]. Similar results were obtained by Salle et al. in 1999 in Senegal under the study of nutritional rehabilitation [13]. Nutritional indices were recalculated after administration of the supplements to the children. The improvement obtained, may be explained by the fact that spirulina is a supplement that is rich both in micronutrients and

Table 2: Results of weight variations throughout the weeks of rehabilitation (after 25 days)

\begin{tabular}{|c|c|c|c|c|c|c|c|}
\hline $\begin{array}{c}\text { Children } \\
\text { Weighing(Kg) }\end{array}$ & 1 & 2 & 3 & 4 & 5 & 6 & 7 \\
\hline$W_{1}$ & 15.5 & 17 & 16 & 15.5 & 20.5 & 19.5 & 16.5 \\
\hline$W_{2}$ & 16.5 & 18.5 & 17 & 16.5 & 21.5 & 21 & 18 \\
\hline$W_{2}-W_{1}$ & 1 & 1.5 & 1 & 1 & 1 & 1.5 & 1.5 \\
\hline$W_{3}$ & 16.5 & 17.5 & 17 & 16.5 & 21 & 20 & 18.5 \\
\hline$W_{3}-W_{2}$ & 0 & 1 & 0 & 0 & -0.5 & -1 & 0.5 \\
\hline$W_{4}$ & 17.5 & 17.5 & 16.5 & 16.5 & 20.5 & 20 & 17.5 \\
\hline$W_{4}-W_{3}$ & 1 & 0 & -0.5 & 0 & -0.5 & 0 & -1 \\
\hline$W_{4}-W_{1}$ & 2 & 0.5 & 0.5 & 1 & 0 & 0.5 & 1 \\
\hline
\end{tabular}

$W_{1}$ : week $1, W_{2}$ : week $2, W_{3}$ : week $3, W_{4}$ : week 4 . 


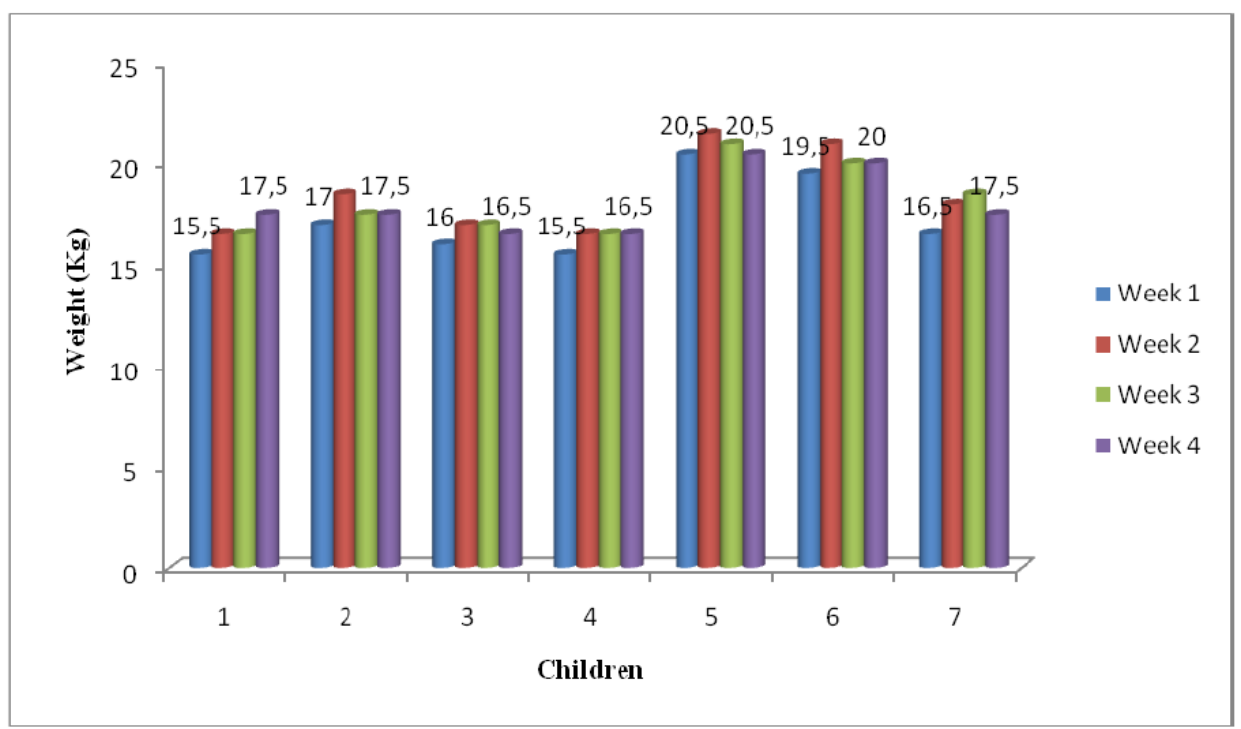

Figure 2: Average children weights for 25 days.

It is observe that from the first to the last day of the experiment, the children weights were increased.

Table 3: Mean Weights and p-value expressed as Mean $\mathrm{Kg} \pm$ Standard deviation

\begin{tabular}{|l|c|c|}
\hline Variables & Mean \pm SD (Kg) & p-value \\
\hline \hline Weight $\left(W_{1}\right)$ & $17.21 \pm 1.99$ & - \\
Weight $\left(W_{2}\right)$ & $18.43 \pm 2.07$ & $0.02^{*}$ \\
Weight $\left(W_{3}\right)$ & $18.14 \pm 1.77$ & $0.02^{*}$ \\
Weight $\left(W_{4}\right)$ & $17.67 \pm 1.93$ & $0.04^{*}$ \\
\hline
\end{tabular}

Compared to the first week all the p-values were less than 0.05 indicating significant differences.

Table 4: Variables before and after Rehabilitation Expressed as Mean \pm Standard Deviation

\begin{tabular}{|c|c|c|c|}
\hline Variables & Before rehabilitation & After réhabilitation & p-value \\
\hline \hline Red blood cell & $9.29 \pm 2.69$ & $9.19 \pm 1.75$ & 0.79 \\
White blood cell & $3.70 \pm 0.41$ & $3.60 \pm 0.34$ & 0.46 \\
Haemoglobin & $10.06 \pm 0.72$ & $10.54 \pm 0.90$ & 0.07 \\
Haematocrite & $31.54 \pm 2.29$ & $30.09 \pm 2.42$ & 0.13 \\
Platelet & $421.71 \pm 86.29$ & $353.71 \pm 97.23$ & 0.09 \\
Neutrophiles & $49.50 \pm 22.78$ & $57.86 \pm 7.01$ & Not available \\
Basophiles & $0.57 \pm 1.51$ & $0 \pm 0.00$ & 0.73 \\
Eosinophiles & $10.57 \pm 18.30$ & $4 \pm 1.52$ & $>0.99$ \\
Monocytes & $4.36 \pm 1.03$ & $4.43 \pm 0.79$ & $>0.99$ \\
Lymphocytes & $35 \pm 6.83$ & $33.71 \pm 8.32$ & 0.06 \\
Total proteins & $62.61 \pm 2.08$ & $69.03 \pm 2.25$ & $0.02^{*}$ \\
Calcium & $73.91 \pm 16.89$ & $88.41 \pm 14.83$ & $0.04^{*}$ \\
MCV(VGM) & $86.14 \pm 4.38$ & $83.86 \pm 4.23$ & 0.10 \\
MCCH(TGMH) & $27.63 \pm 1.27$ & $28.66 \pm 2.74$ & $0.03^{*}$ \\
MCHC & $32.10 \pm 0.38$ & $34.27 \pm 3.35$ & \\
\hline
\end{tabular}

MCV: mean cell volume, $\mathrm{MCCH}$ : mean cell content in haemoglobin, $\mathrm{MCHC}$ : mean cell haemoglobin concentration, RBC: red blood cell, WBC: white blood cell * significant; Values are expressed as Mean \pm Standard Deviation (SD).

macronutrient. It contains high percentage of macronutrient (especially proteins which is $60-70 \%$ ) and micronutrient (especially iron, calcium and magnesium).
On the other hand, a similar study on 52 HIVpositive patients compared a group supplemented with spirulina and a group supplemented with soya beans [11]. This work showed a comparable efficacy for 
spirulina and soya beans as regards weight gain, but also a significant increase in immunological markers for the group treated with spirulina, and not with the group treated with soya beans.

The gain in proteins and weight obtained in the course of this study was similar to the result observed by $[11,13]$. However, the child whose total proteins experienced a decrease after rehabilitation was also had low calcium was found bonded or linked with protein during its metabolism. Studies had shown that, there are statistically significant correlations between calcium and total proteins and between calcium and albumin in normal subjects, but the correlation coefficients are low (less than 04) and because of the limited ranges of the observed values the regression lines cannot be extrapolated with confidence to low proteins concentrations [14]. Keating and colleague also reported a relation between calcium and total proteins, calcium and albumin in patients who showed a wide range of abnormalities of proteins concentration.

Individual calcium needs are affected by the rate of growth, the degree of absorption, and the availability of other nutrients, including vitamin D and phosphorus, as well as calories and proteins. Dietary substances that may decrease calcium retention include caffeine, excessive phosphorus intake, oxalic and phytic acids, and proteins [15]. When the content of calcium in a diet is poor, it affects the synthesis of red blood cells which takes place at the bone marrow. After rehabilitation, the concentration of calcium of 6 children had increased significantly as seen above. This was due to the fact that the nutrient content of Spirulina in terms of calcium is high $(1000 \mathrm{mg} / 100 \mathrm{~g}$ of spirulina) [11]. The increase in calcium blood content simply implies that, calcium has been absorbed by the body after ingestion of spirulina. This has also gone a long way to show the high absorption and digestibility of spirulina in the body.

The levels of haematocrit (PCV) of six children out of seven were below the cut-off point level while only one child had normal cut off point value after rehabilitation. Low values of PCV (anaemia) are indicative of bacterial infections and gastrointestinal disorders, including parasitism and haemorrhage [16], or may reflect nutritional deficiencies of minerals like iron or copper [17]. This suggested that malnutrition in the Orphelinat la Compassion may also be due to frequent infections.

There was a decrease in platelets value for all the children excepting child 2(from 333 to $428 \mathrm{~mm}^{3}$ ) where an increase is observed. This increase can be explained by the effect of spirulina on biomarkers (platelets) where it leads to hematopoiesis including platelets [18]. No matter the decrease in platelet, the children still maintain their cut-off point of platelets and none of them was observed to have value below the cut-off level.

An increase in RBC was observed in the following child 1 (from 3.55 to 3.80 ), child 2(from 3.24 to 3.29 ), and child 6 (from 3.65 to 3.71 ), while RBC for child 7 (from 3.54 to 3.54 ) remained constant. Spirulina platensis has an increasing effect on many of the analysed biomarkers, including RBC. This was also observed in other works as long as beneficiaries were in deficit [13]. In another similar study improvement of haematopoiesis was observed (production function of a blood and oxygen transport) [18]. A deficiency in oxygen-carrying red blood is defined as iron deficiency anaemia (IDA). It is the most common cause of anaemia which is frequently related to vitamin B12 or folate deficiency. Two boys of 5 years old had abnormal RBC values $\left(3.04\right.$ and $3.29 \times 10^{6} \mathrm{~mm}^{3}$ ), below the cut-off after rehabilitation which can be interpreted as anemia. Their initial values were 3.47 and 3.24 respectively. They fall sick the second week of the study. Common factors leading to IDA include insufficient iron intake or poor dietary sources of iron (e.g., vegetarian/vegan diet), early introduction of whole cow's milk [19, 20].

The increase of WBC was influenced by the spirulina intake which set off the activation of immune system defense function, as observed elsewhere [21].

The increase in neutrophiles, eosinophile above the normal range of child 6 , is due to reinforcement, activation of the immune system by spirulina as reported in previous studies, reason for slight elevation [21]. Many studies carried out using animals by Pascaud in 1993 and Borchers et al. in 2007 had also shown similar results with the reinforcement of the immune system after administration of spirulina [22, 23].

The results of basophile before and after rehabilitation of the 7 children were respectively 0.0 except for child 1 , where the value before rehabilitation was 4 beyond the cut-off point. This implies that there were infections before rehabilitation, while after rehabilitation the values were reduced significantly after healing of infections as described by [24].

The increase of monocytes observed with the administration of spirulina may be due to the set off of 
the immune defence's activation. This activity was demonstrated by many authors, after they have studied a polysaccharide (Immulina) compound derived from spirulina as set off of immune defences $[18,25,26]$.

After administration of spirulina, we had the following values for lymphocytes: $27,42,42,41,25,31$ and $44 \%$ respectively for each child (1 to 7 ). The increase for and decrease observed in children was due the effect spirulina on defence and maintenance of an immune system as described previously in other studies [27, 28].

The decrease of MCV $\left(<80 \mu \mathrm{m}^{3}\right)$ observed usually seen in microcytic anaemia due to iron deficit or during inflammatory syndrome and thalassemia. MCV defines the average volume of RBC's. Defining anaemia as micro, normo or macrocytic is the initial step in diagnosing ID. After rehabilitation we observed the following results for $\mathrm{MCV}$ respectively in the same order for 7 children (1 to 7): 27.6, 29.7, 34, 28.8, 26.2, 25.8 and $28.5 \mathrm{pg}$. However, the normal value of $\mathrm{MCCH}$ ranges between 26-36 pg. An increase in $\mathrm{MCCH}$ was noticed in all the children except child 6 whose value decreases from 26.2 to 25.8. The children having their $\mathrm{MCCH}$ values below the cut-off point may had microcytic anaemia and they also include child 4(25.9) and $5(25.8)$ before rehabilitation.

MCHC test reveals after rehabilitation the following results: $32.9,32.5,41.2,36.1,32.0,32.8$ and $32.4 \mathrm{~g} / \mathrm{dL}$. The normal cut-off point is $31.5-37 \mathrm{~g} / \mathrm{dL}$. The results showed that all values are normal despite the increase (effect of spirulina on biomarkers).

\section{CONCLUSION}

Supplementation with spirulina in less than five years old children have shown to play a beneficial role in the fight against malnutrition (protein energy malnutrition and micronutrient deficiency). Further studies, involving more subjects and for a longer duration, are needed to replicate these results and uncover the underlying mechanisms involved.

\section{ACKNOWLEDGEMENTS}

We are grateful to the mother responsible for "La compassion" orphanage Mrs. Biejwe Madeleine for allowing her children to participate in our study. Our gratefulness equally goes to all students who participated to this study in a way or the other. This was a satellite pilot supplementary study to prepare a community implementation, of a project funded by
Nestlé Foundation to reduce young children malnutrition in Bangang Rural community.

\section{REFERENCES}

[1] WHO, De Onis M, Monteiro C, Clugston G. The worldwide magnitude of protein energy malnutrition: an overview from the WHO global database on child growth Bull 1993; 71(6): 703-12.

[2] Kana Sop MM, Gouado I, Mananga MJ, Ecoule LD, Amvam Zollo PH, Tetanye E. Evaluation of nutritional status of young children age $0-5$ years in the Douala city (Cameroon), Survey of some practice during diversification of complementary food. African Journal of Food Science and Technology 2013; 4(2): 29-34.

[3] UNICEF. La malnutrition responsable de la moitié des décès. www.unicef.fr/la-malnutrition-responsable-de-la-moitie-desdeces-d'enfants 2011.

[4] WHO. Iron deficiency anaemia: assessment, prevention, and control. A guide for programme managers. Geneva: World Health Organization (WHO/NHD/01.3) 2001.

[5] UNICEF. Progress for Children: A world fit for children statistical review. New York: United Nations Children"s Fund 2007.

[6] Hug C, Denis VD. Spirulina in the fight against malnutrition assessment and prospect 2011: 3-5.

[7] Scrimshaw S, Taylor E, Gordon E. Interaction between nutrition and infection. Geneva, WHO monograph series: 1968; 143-183.

[8] Michaelsen KF, Hoppe C, Roos N. Choice of Foods and Ingredients for Moderately Malnourished Children 6 Months to 5 Years of Age. In: Food and Nutrition Bulletin 2009; (30): 1029-102.

[9] Annapuna V, Shah N, Bhaskaram P. Bioavailability of Spirulina carotenes in pre-school children. J Clin Biochem Nutr 1991; 10: 145-151. http://dx.doi.org/10.3164/jcbn.10.145

[10] Hasler C. Functional foods: benefits, concerns and challenges a position paper from the American Council on Science and Health 2002; 132: 3772-3781.

[11] Azabji Kenfack M, Edie Dikosso S, Loni EG. Potential of Spirulina Platensis as a Nutritional Supplement in Malnourished HIV-Infected Adults in Sub-Saharan Africa: A Randomised, Single-Blind Study. In: Nutrition and Metabolic Insights 2011; 4: 29-37

[12] Halidou DM, Degbey $H$, Leveque A, Donnen $P$, Hennart $P$, Dramaix WM. The effect of spiruline during nutritional rehabilitation: Systematic review. Revue d'Épidémiologie et de Santé Publique 2008; 56: 425-431.

[13] Sall MG, Dankoko B, Badiane M, Ehua E, Kuakuwi N. Résultats d'un essai de réhabilitation nutritionnelle avec la Spiruline à Dakar. Médecine d'Afrique Noire 1999; 46: 143146.

[14] Keatinge WR, Mcllroy MB, Goldfien A Cardiovascular response to ice-cold showers. J Appi Physiol 1964; 19: 114550 .

[15] Mitchell MK. Nutrition across the life span. Philadelphia: W.B. Saunders Company 2003; pp. 4-11.

[16] Dein J. Haematology. Clinical Avian Medicine. Harrison GJ, Harrison WR, Eds. Saunders, London 1986; pp. 174-191.

[17] Sturkie PD, Griminger P. Body fluids: Blood Avian Physiology, $4^{\text {th }}$ ed. Sturkie PD, Ed. Springer-Verlag, New York 1986; pp. 103-129.

http://dx.doi.org/10.1007/978-1-4612-4862-0

[18] Zhang HQ, Lin AP, Sun Y, Deng YM. Chemo- and radioprotective effects of polysaccharide of Spirulina platensis on hemopoietic system of mice and dogs. Acta Pharmacological Sinica 2001; 22: 1121-1124. 
[19] Tunnessen WW, Oski FA. Consequences of starting whole cow milk at 6 months of age. J Pediatr 1987; 111(6): 813-6. http://dx.doi.org/10.1016/S0022-3476(87)80193-2

[20] Pizarro F, Yip R, Dallman PR. Iron status with different infant feeding regimens: relevance to screening and prevention of iron deficiency 1991; 118(5): 687-92.

[21] Qureshi MA, Garlich JD, Kidd MT. Dietary Spirulina platensis enhances humoral and cell-mediated immune functions in chickens. Immunopharmacology and Immunotoxicology 1996; 18: 465-476.

http://dx.doi.org/10.3109/08923979609052748

[22] Pascaud M. The essential polyunsaturated fatty acids of Spirulina and our immune response 1993; pp. 1-32.

[23] Borchers AT, Belay A, Keen CL, Gershwin ME. Spirulina and Immunity in Gershwin and Belay. Spirulina in Human Nutrition and Health 2007; 177-193.

[24] Hayashi T, Hayashi K, Maeda M, Kojima I. Calcium spirulan, an inhibitor of enveloped virus replication, from a blue-green alga Spirulina platensis. Journal of Natural Products 1996; 59: 83-87.

http://dx.doi.org/10.1021/np960017o
[25] Plugh N, Ross SA, EISohly HN, ElSohly MA, Pasco DS. Isolation of three high molecular weight polysaccharide preparations with potent immunostimulatory activity from Spirulina platensis, Aphanizomenon flos-aquae and Chlorella pyrenoidosa 2001: 67: 737-742.

[26] Lobner M, Walsted A, Larsen R, Bendtzen K, Nielsen $\mathrm{CH}$. Enhancement of Human Adaptive Immune Responses by Administration of a High-Molecular-Weight Polysaccharide Extract from the Cyanobacterium Arthrospira platensis Journal of Medicinal Food 2008; 11(2): 313-322. http://dx.doi.org/10.1089/jmf.2007.564

[27] Harrigan GG, Luesch H, Yoshida WY, Moore RE, Nagle DG Paul VJ. Symplostatin 2: a dolastatin 13 analogue from the marine cyanobacterium Symploca hydnoides 1999; 62: 655658.

[28] Degbey H, Hamadou B, Oumarou H. Evaluation de l'efficacité de la supplémentation en Spiruline du régime habituel des enfants atteints de malnutrition sévère. In Charpy et al. (ed.) International Symposium on Cyanobacteria for Health, Science and Development 2006; 104-108. 